\title{
Q-Switched 1,064-nm Neodymium-Doped yttrium aluminum garnet laser irradiation induces collagen remodeling in SKH-1 Hairl ess mice by activating ERK1/2 and p38MAPK signaling pathway
}

\author{
Ruilei HUANG ${ }^{1}$, Yang $\mathrm{LIU}^{2}$, Zhijie $\mathrm{LIU}^{3}$, Ying ZHAO ${ }^{3 *}$
}

\begin{abstract}
To select the optimal condition of $1064 \mathrm{~nm}$ Q-switched Nd:YAG laser irradiation and study the molecular mechanism of laser irradiation for skin rejuvenation. Sixty male, 6 -week-old SKH-1 hairless mice were equally divided into 6 groups: $3 \mathrm{~d}, 7 \mathrm{~d}, 21 \mathrm{~d}$, $28 \mathrm{~d}, 42 \mathrm{~d}$ and $56 \mathrm{~d}$ of $1064 \mathrm{~nm}$ laser irradiation at both $0 \mathrm{~J} / \mathrm{cm}^{2}$ (left region) and $1.5 \mathrm{~J} / \mathrm{cm}^{2}$ (right region) fluence. The basic skin performances were analysed via quantifying hydroxyproline content and skin hydration in the dermis and epidermis. The Collagen I, MMP2 and TIMP1, as well as ERK 1/2, p38MAPK, JNK and ERK5 signaling pathways levels were detected by qRT-PCR. Laser irradiation led to a marked increase in hydroxyproline content and skin hydration in the dermis and epidermis compared to the non-irradiated area. After laser irradiation, collagen I was markedly up-regulated, MMP2 was significantly decreased and TIMP1 was unchanged. Moreover, qRT-PCR results revealed ERK 1/2 and p38MAPK signaling pathways were activated after laser irradiation. we are firstly proves that $1064 \mathrm{~nm}$ laser irradiation can inhibit collagen degradation by stimulating the activation of ERK1/2 and p38MAPK signaling pathways. Additionally, the condition of laser irradiation lasting $21 \mathrm{~d}$ at fluence of $1.5 \mathrm{~J} / \mathrm{cm}^{2}$ displays the best effect of skin rejuvenation in our study.
\end{abstract}

Keywords: SKH-1 hairless mice; 1064 nm Q-switched Nd:YAG laser; collagen remodeling; ERK 1/2; p38MAPK signaling pathways.

Practical Application: Neodymium-Doped Yttrium Aluminum Garnet Laser Irradiation Induces Collagen Remodeling.

\section{Introduction}

Skin aging is divided into natural aging (genetic factor) and photo-aging (environmental factor). Genetic aging of skin results from personal genetics, and the deterioration of natural inherent repair and regenerative processes. Environmental aging of skin is defined as skin aging following chronic exposure to ultraviolet solar rays from natural or artificial sunlight with manifestations as skin laxity, pigment abnormalities, wrinkles, telangiectasia and pore enlargement. Moreover, natural aging and photo-aging occupy similarities in histopathology including decreased elasticity, reduction of secretion from sebaceous glands and sweat glands, elastic fiber denaturation, reduced collagen content, lipid peroxidase and denatured protein deposition in the skin, etc. (Farage et al., 2013; Tao et al., 2015). Skin rejuvenation is a therapeutic method of improving and reversing shin aging and mainly includes two categories: delaying cell senescence by regulating on cell and molecular levels, doing structure remodeling according to the skin structure changes (Yaar \& Gilchrest, 2007). In present study, we mainly focused on molecular levels changes of the dermis and epidermis to elucidate skin rejuvenation.

Q-switched 1064-nm neodymium-doped yttrium aluminum garnet laser (Nd: YAG) belongs to infrared light, non-ablative laser which is the most popular technology of skin rejuvenation because of its relatively longer wavelength and higher energy peak, and fairly strong penetrating power. On a large scale, Q1064 $\mathrm{nm}$ laser therapy is a photodynamic and electrodynamic treatment technology. Its targets are water molecules that located in the superficial layer of dermis. Under the condition of without affecting the epidermal layer, it can promote dermal new collagen formation to commendably solve the problems of skin erythema for a long time, pigmentation after inflammation, skin infection and scarring. It is effective for removing skin fine lines and improving skin texture (Goldberg \& Silapunt, 2001; Zhou \& Yang, 2015). Meanwhile, Goldberg and colleagues demonstrated that 1,064-nm Q-switched Nd: YAG laser promoted cosmetic improvement in wrinkle appearance in several studies (Goldberg \& Metzler, 1999; Goldberg \& Silapunt, 2000). Additionally, Goldberg D, et al.have also documented that the 1,064-nm Nd: YAG laser induced collagen production and slight fibrosis in the dermis by histological studies (Goldberg \& Silapunt, 2001). Moreover, Gold MH, et al.reported that the non-ablative fractional Q-switched 1064-nm Nd: YAG laser is safe and effective for improving signs of mild-to-moderate photodamage skin irregularities without significant downtime, pain, or adverse side effects (Gold et al., 2014). Therefore, $1064 \mathrm{~nm}$ Q-switched Nd:YAG laser irradiation maybe a safe and effective therapeutic method for ameliorating skin aging. 
Although various etiologies can cause skin aging, common points include less expression of dermal type I collagen (Collagen I), greater matrix metalloproteinase (MMP) and tissue inhibitors of metalloproteinase (TIMP) (Jenkins, 2002; Quan et al., 2004; Rhee et al., 2016). Skin collagen provides skin strength and elasticity in the form of elongated fibrils, and the gradual loss of collagen in skin brings aging results in wrinkles and other signs of skin aging. Thus, one important target of increasing dermal collagen production and reducing its breakdown may be the key action for the non-ablative techniques (Dang et al., 2011; Alam et al., 2003). In previous research, $1064 \mathrm{~nm}$ Q-Switched $\mathrm{Nd}$ :YAG laser was used to irradiate the dorsal skin of BABL/c mice with $0,1,1.5$ and $2 \mathrm{~J} / \mathrm{cm}^{2}$ energy level and lasting for 7 , 14,21 , and 28 days, respectively. Then, they found from 21 days to 28 days, the skin elasticity, moisture content, hydroxyproline content, and gene expression of types I and III procollagen increased significantly. $1064 \mathrm{~nm}$ Q-Switched Nd:YAG laser could markedly promote repair of mice skin within 28 days through stimulation of collagen synthesis with fewer skin barrier dysfunction and the best irradiation condition of this laser was lasting for $21 \mathrm{~d}$ under $1.5 \mathrm{~J} / \mathrm{cm}^{2}$ fluence (Wang et al., 2016). However, the irradiation effects of this laser before 7 days and after 28days under $1.5 \mathrm{~J} / \mathrm{cm}^{2}$ energy level is waiting for further study, and the underlying mechanism of new collagen formation by laser irradiation for photorejuvenation is still unclear.

The proposed L-arginine dose may be of importance in skin rejuvenation approaches and wound healing associated with significant upregulation of Extracellular signal-Regulated Kinase (ERK), phosphor-ERK (p-ERK) and c-Jun N-terminal kinases (JNK) while no significance of the rise in phosphor-JNK (pJNK) kinase (Kocic et al., 2017). Moreover, for scar amelioration and skin rejuvenation in acne treatment, Ce6-mediated Photodynamic Therapy (PDT) with halogen light enhanced collagen production, in a dose dependent manner, inhibited P. acnes-induced phosphorylation of JNK and ERK (Ryu \& Lee, 2017). In Low-Level Laser Terapy (LLLT) enhancing wound healing and stimulating cell proliferation of fibroblast and endothelial cells, ERK and Mitogen-Activated Protein Kinase (MAPK) phosphorylation were increased while the TNF/CHX-increased p38 MAPK, JNK, IKK phosphorylation, NF- $\kappa \mathrm{B}$ translocation, and iNOS expression was suppressed. This showed that LLLT protects against inflammatory-induced endothelial dysfunction by suppressing p38MAPK signaling (Chu et al., 2018). Moreover, the upregulation of signaling proteins (PKBa and ERK5) were reported for damaged tissue protection and brain tissue recovery (Demyanenko et al., 2015). Irradiation with a high-frequency Near-Infrared (NIR) diode laser increased cell division and migration of MT3T3-E1 cells, possibly be related to the phosphorylation of MAPK/ERK1/2 (Kunimatsu et al., 2018). However, whether the signaling pathways of ERK1/2, p38MAPK, JNK and ERK5 involved in Q-switched 1064-nm Nd: YAG laser treating skin aging for skin rejuvenation is waiting for research. Thus, based on the previous research, we will add several points of $3 \mathrm{~d}, 42 \mathrm{~d}$ and $56 \mathrm{~d}$ to demonstrate the possible mechanism of Q-switched 1064-nm Nd: YAG laser for hairless micement-related skin rejuvenation in epidermal and dermal tissue. Basic data representations were detected by skin hydration and hydroxyproline content. In addition, collagen remodeling after laser treatment was observed using real-time quantitative reverse transcription-polymerase chain reaction (qRT-PCR) to analyze the expression of collagen 1 and corresponding proteins of MMP2 and TIMP1 from dermis and epidermis tissues. Finally, the signal pathway performances were detected by the RNAs of ERK1/2, p38MAPK, JNK and ERK5 using qRT-PCR.

\section{Materials and methods}

\subsection{Animals and groups}

Sixty male, 6-week-old SKH-1 hairless mice were provided from Shanghai Public Health Clinical College. All mice were raised for at least one week in a temperature-controlled room at $25{ }^{\circ} \mathrm{C}$ and $60 \%$ relative humidity with $12 \mathrm{~h}$ light cycle and given free access to standard laboratory diet and water before experiments. The mice were treated according to the ethical guidelines of the animal center, Shanghai Public Health Clinical College, and the Animal Studies Committee of Shanghai Public Health Clinical College approved the experimental protocol. In addition, all mice were divided into six groups of irradiation $3 \mathrm{~d}$, $7 \mathrm{~d}, 21 \mathrm{~d}, 28 \mathrm{~d}, 42 \mathrm{~d}$ and $56 \mathrm{~d}$ with each group including 10 mice, and each mouse of groups was received 1064-nm Nd: YAG laser at fluence of $0 \mathrm{~J} / \mathrm{cm}^{2}$ and $1.5 \mathrm{~J} / \mathrm{cm}^{2}$.

\subsection{Laser irradiation}

Sixty mice were anesthetized intraperitoneally with $1 \%$ $(1 \mathrm{~mL} / \mathrm{kg}$ ) chloral hydrate and their dorsal surfaces were equally divided into two areas by a marker pen. The left region was used as a control without laser irradiation $\left(0 \mathrm{~J} / \mathrm{cm}^{2}\right.$ fluency) and the right area was treated using the 1064-nm Nd: YAG laser (Medlite $\mathrm{IV}$, Conbio, USA) with a $5 \mathrm{~ns}$ pulse width at $1.5 \mathrm{~J} / \mathrm{cm}^{2}$ fluency. The spot size was kept at a constant diameter of $6 \mathrm{~mm}$, and the irradiation duration was fixed at $1 \mathrm{~s}$. Irradiation were performed lasting 3d, 7d, 21d, 28d, 42d and 56d on each group of mice, separately, at an interval of 1 day. A dynamic cooling device (Cryogen; Candela) sprayed cryogen before and after the laser irradiation to cool the epidermis.

\subsection{Skin hydration}

All mice were received the measurement of skin hydration in the dermis and epidermis in triplicate after eventual laser irradiation by using a skin capacitance measuring device (Corneometer 820PC; Courage \& Khazaka Electronic GmbH). This device can quantify the humidity levels of the stratum corneum based on the distinct dielectric constant of the water. Moreover, there were at least 20 min' acclimatization period in an air-conditioned room under standardized conditions $\left(22-25^{\circ} \mathrm{C}, 50 \%\right.$ humidity) before measurement. Each measurement was performed on the left and right areas of each subject (Shin et al., 2012).

\subsection{Hydroxyproline content}

Each mouse was anesthetized intraperitoneally with $1 \%$ $(1 \mathrm{~mL} / \mathrm{kg})$ chloral hydrate after the eventual laser irradiation. The dorsal surface skin from left and right areas was taken for $100 \mathrm{mg}$, separately, to detect the skin hydroxyproline content 
in the dermis and epidermis according to the instructions of hydroxyproline kit.

\section{$2.5 q R T-P C R$}

Based on the results of skin hydration and hydroxyproline content, we will select the best irradiation condition that lasting $21 \mathrm{~d}$ group to perform qRT-PCR experiment. Total RNA was isolated from dermis and epidermis tissue using the RNeasy Mini Kit (Qiagen) following the manufacturer's instructions. First-strand cDNA for real-time PCR was generated using $1 \mu \mathrm{g}$ of total RNA and SuperScript VILO MasterMix (Invitrogen). The mRNA expression levels of Collagen I, MMP2, TIMP1, ERK1/2, p-ERK1/2, p38MAPK, p-p38MAPK, JNK, p-JNK, ERK5 and p-ERK5 were assessed by qRT-PCR. The QuantStudio ${ }^{\text {mi }} 7$ Flex Real-Time PCR system (Life Technologies) were used and qRT-PCR was performed using the "Fast" program: $95^{\circ} \mathrm{C}$ for $20 \mathrm{~s}$, followed by 40 cycles of $95^{\circ} \mathrm{C}$ for $1 \mathrm{sec}$ and $60^{\circ} \mathrm{C}$ for $20 \mathrm{~s}$. Data were normalized and quantified by using 2- $\Delta \Delta \mathrm{Ct}$ method and GAPDH was utilized as an internal control. The sequences of primers used in this study could be seen in Table 1. The PCR assays were performed for three times.

\subsection{Statistical analysis}

Statistical analyses were performed with SPSS 19.0 software. The values in the experiments are expressed as means \pm SD. Statistical evaluation of the data was performed using One-way ANOVA and LSD-q test, $p<0.05$ was considered significant.

\section{Results: the skin rejuvenation effect of Q1064 nm laser on dorsal surface skin of mice}

The skin rejuvenation effect presented a wavy similar to normal distribution trend with the extension of laser irradiation time. The best skin rejuvenation effect appeared at the third week or on day 21 of irradiation, and after exposure to $28 \mathrm{~d}$, the increasing rate of skin hydration and hydroxyproline acid content were slightly reduced. To 56d, skin hydration and hydroxyproline acid content were increased obviously compared to $28 \mathrm{~d}$ group (Figure 1). Therefore, the best irradiation condition group (irradiation lasting 21d group) will be selected for the next experiment.

\subsection{Collagen remodeling molecules expression levels of collagen I, MMP2 and TIMP1 detected by $q R T-P C R$}

The qRT-PCR results showed an increased expression level of collagen I $(\mathrm{P}<0.01)$, reduced expression level of MMP-2 $(\mathrm{P}<0.05)$, and unchanged expression level of TIMP-1 $(\mathrm{P}>0.05)$ in dermis and epidermis from 1064-nm Nd: YAG laser irradiation region compared to non-irradiated region $\left(0 \mathrm{~J} / \mathrm{cm}^{2}\right)$ (Figure 2).

\subsection{The expression levels of signaling pathways of ERK 1/2, p38MAPK, JNK and ERK5 which involving in collagen remodeling detected by $q R T-P C R$}

Q-switched 1064-nm Nd: YAG laser had no effect on the mRNA expression level of ERK1/2 and p38MAPK from dermis and epidermis compared to non-irradiated area $\left(0 \mathrm{~J} / \mathrm{cm}^{2}\right)(\mathrm{P}>0.05)$,

Table 1. The sequences of primers used for qRT-PCR.

\begin{tabular}{cll}
\hline Gene names & \multicolumn{1}{c}{ Forward } & \multicolumn{1}{c}{ Reverse } \\
\hline GAPDH & 5'-GGAGAAACCTGCCAAGTATG-3' & 5'-GACAACCTGGTCCTCAGTGT-3' \\
Collagen I & 5'-GGAATCCGGGGTTTACCTGG-3' & 5'-AGGCGACCCTCTGATACCTT-3' \\
MMP2 & 5'-ACACTGGGACCTGTCACTCC-3' & 5'-TGTCACTGTCCGCCAAATAA-3' \\
TIMP1 & 5'-GCATCTCTGGCATCTGGCATC-3' & 5'-GCGGTTCTGGGACTTGTGGGC-3' \\
P38MAPK & 5'-TCGAGACCGTTTCAGTCCAT-3' & 5'-CCACGGACCAAATATCCACT-3' \\
ERK1 & 5'-GGGAGATCCAGATCCTGCT-3' & 5'-GGTCAGTCTCCATCAGGTCC-3' \\
ERK2 & 5'-ACCAACCTCTCGTACATCGG-3' & 5'-CTGGCAGTAGGTCTGGTGCT-3' \\
JNK & 5'-AGCAGAAGCAAACGTGACAAC-3' & 5'-GCTGCACACACTATTCCTTGAG-3' \\
ERK5 & 5'-CTGGCTGTCCAGATGTGAA-3' & 5'-ATGGCACCATCTTTCTTTGG-3' \\
\hline
\end{tabular}

p38MAPK = p38 mitogen-activated protein kinase; ERK = extracellular signal-regulated kinase; JNK = c-Jun N-terminal kinases.

A

B

The increasing rate of skin hydration(\%) The increasing rate of hydroxyproline acid content $(\%)$
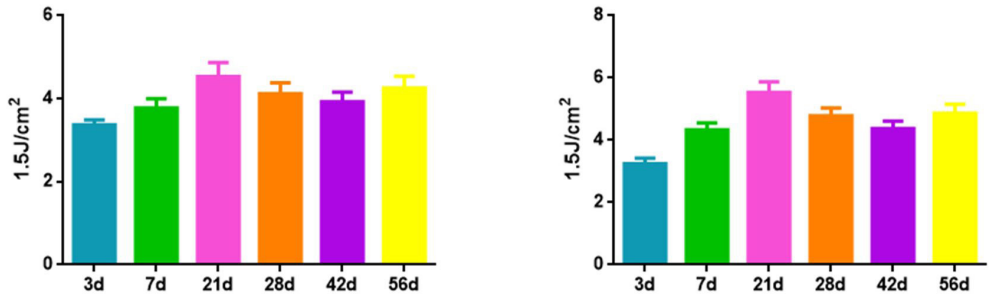

Figure 1. The skin condition indicators in the dermis and epidermis after Q1064 nm laser irradiation. (A) The increasing rate of skin hydration in different Q1064 nm laser irradiation group; The increasing rate of skin hydration: in same group, (the skin hydration content under $1.5 \mathrm{~J} / \mathrm{cm}^{2}$ - the skin hydration content under $0 \mathrm{~J} / \mathrm{cm}^{2}$ fluency)/ the skin hydration content under $0 \mathrm{~J} / \mathrm{cm}^{2}$ fluency; (B) The increasing rate of hydroxyproline acid content in different Q1064 nm laser irradiation group; The increasing rate of hydroxyproline acid content: in same group, (the hydroxyproline acid content under $1.5 \mathrm{~J} / \mathrm{cm}^{2}$ - the hydroxyproline acid content under $0 \mathrm{~J} / \mathrm{cm}^{2}$ fluency)/ the hydroxyproline acid content under $0 \mathrm{~J} / \mathrm{cm}^{2}$ fluency. 


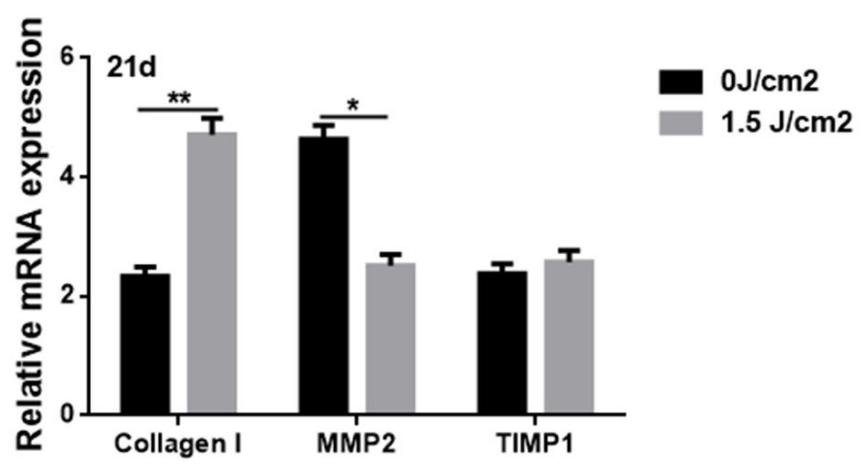

Figure 2. The relative mRNA expression of Collagen I, MMP2 and TIMP1 in dermis and epidermis of mice who suffered from Q1064 nm laser irradiation for $21 \mathrm{~d} ;{ }^{* *} 1.5 \mathrm{~J} / \mathrm{cm}^{2}$ vs $0 \mathrm{~J} / \mathrm{cm}^{2}, \mathrm{P}<0.01$; ${ }^{\star} 1.5 \mathrm{~J} / \mathrm{cm} 2$ vs $0 \mathrm{~J} / \mathrm{cm}^{2}, \mathrm{P}<0.05$.

whereas phosphorylation level of ERK1/2 and p38MAPK was higher than non-irradiated area $\left(0 \mathrm{~J} / \mathrm{cm}^{2}\right)(\mathrm{P}<0.05)$. Meanwhile, the mRNA expression level of JNK and ERK5 as well as the phosphospecific JNK and ERK5 had no changes $(\mathrm{P}>0.05)$ (Figure 3).

\section{Discussion}

Skin aging is something everyone has to experience, and skin aging involves intrinsic and extrinsic processes. Genes largely determine intrinsic aging, and environmental factors, primarily ultraviolet (UV) light from natural or artificial sunlight, cause extrinsic aging with manifestations as skin laxity, pigment abnormalities, wrinkles, telangiectasia and pore enlargement and with histopathology changes including decreased elasticity, reduction of secretion from sebaceous glands and sweat glands, elastic fiber denaturation, reduced collagen content, lipid peroxidase and denatured protein deposition in the skin ,etc. (Farage et al., 2013; Jenkins, 2002; Tao et al., 2015). Thus, for many people, how to maintain or restore a youthful appearance has become an obsession. Meanwhile, the effective treatments to rejuvenate the skin aging without adverse events has long been a need.

Q-switched 1064-nm Nd: YAG laser is a laser system that more applied to clinic at present. It is often used in the treatment of pigmentary disorders such as nevus of Ota and cafe-au-lait spots, etc., and non-ablative skin rejuvenation treatment, and it has advantages of low adverse reactions, high safety and excellent effect (Chan et al., 2003; Ee et al., 2006). The principle of skin rejuvenation of non-ablative laser is that energy penetrates the epidermis and directly acting on elastic fibers and collagen fibers in dermis under the thermal interaction of laser. Meanwhile, collagen comes up reversible thermal degeneration by biostimulation of heating effect and photochemical action produced by laser, that leads to the recombination and proliferation, relaxation and thickening of collagen fibers in dermis, and then lets it rearranging and restoring normal skin elasticity to reduce wrinkles to achieve skin rejuvenation (Alam \& Dover, 2003; Alam et al., 2003; Nikolaou et al., 2005). So, 1064-nm Nd: YAG laser irradiation may be a safe and effective strategy for realizing skin rejuvenation via enhancing collagen remodeling. In this study, we selected a fluence of $1.5 \mathrm{~J} / \mathrm{cm}^{2}$ for applying to $1064 \mathrm{~nm}$

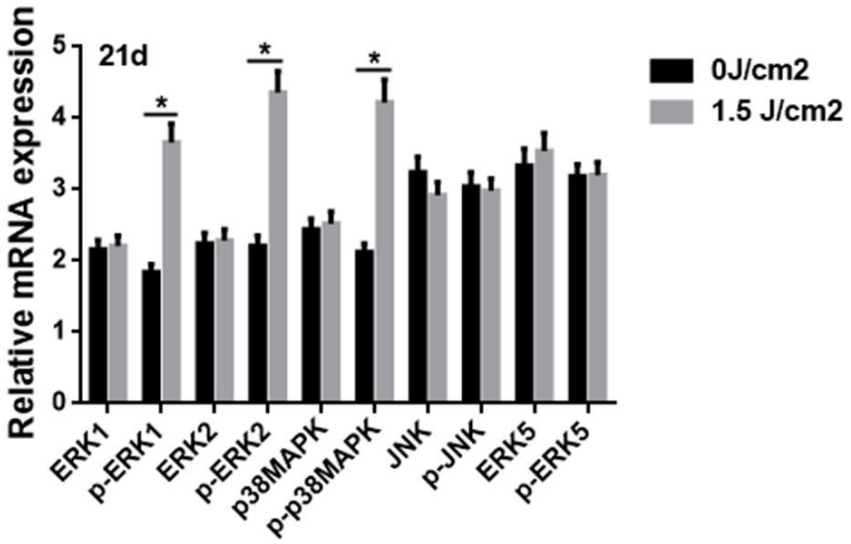

Figure 3. The relative mRNA expression of Signaling Pathways of ERK $1 / 2$, p38MAPK, JNK and ERK5 in dermis and epidermis of mice who suffered from Q1064 $\mathrm{nm}$ laser irradiation for $21 \mathrm{~d}$; ${ }^{\star} 1.5 \mathrm{~J} / \mathrm{cm} 2 \mathrm{vs} 0 \mathrm{~J} / \mathrm{cm}^{2}$, $\mathrm{P}<0.05$.

Q-switched Nd:YAG laser irradiation, and added several time points of $3 \mathrm{~d}, 42 \mathrm{~d}$ and $56 \mathrm{~d}$ for sustained laser irradiation based on the previous report (Wang et al., 2016) to further confirm if irradiation for $21 \mathrm{~d}$ is the best irradiation condition of this laser for obtaining skin rejuvenation. Besides, for detecting skin rejuvenation, we mainly detected the contents of collagen and skin moisture from dermis and epidermis, as well as collagen remodeling-related genes. For molecular mechanism study, ERK 1/2, p38MAPK, JNK and ERK5 signaling pathways will be measured.

Hydroxyproline is one of the main and relatively constant amino acid in collagen and has the little content in other proteins. The content of hydroxyproline is sensitive biochemical indexes to reflect the changes of collagen, and the 7.46 times hydroxyproline content is commonly used to represent the content of collagen (Zhen, 1997). Furthermore, skin moisture ameliorated more visibly, the skin rejuvenation degree are more better (Barone et al., 2019). In this experiment, the content of collagen fibers in dermis and epidermis was estimated by the content of hydroxyproline in collagen. The results showed that hydroxyproline content and skin hydration were increased significantly compared to non-irradiated area. These indicators results presented a wavy similar to normal distribution trend with the extension of laser irradiation time, and the peak of wave was appeared on $21 \mathrm{~d}$ of irradiation. The best laser irradiation condition was lasting for $21 \mathrm{~d}$ under $1.5 \mathrm{~J} / \mathrm{cm}^{2}$ fluence. (Figure 1). This wavy similar to normal distribution trend may be related to the thermal damage produced by the 1064-nm laser (Lee et al., 2014). This study confirmed that Q- switch $1064 \mathrm{~nm} \mathrm{Nd:} \mathrm{YAG}$ laser can improve skin rejuvenation by increasing the content of collagen fiber and skin hydration in dermis and epidermis, which is consistent with the previous perspectives (Zhen, 1997; Barone et al., 2019).

Previous studies have suggested that Q- switch $1064 \mathrm{~nm} \mathrm{Nd:}$ YAG laser non-ablative rejuvenation is associated with histological improvement and new collagen production (Alam et al., 2003; Goldberg \& Silapunt, 2001; Oh et al., 2007). Human skin fibroblasts display greater collagen expression after QS 1,064-nm 
Nd:YAG laser irradiation using RT-PCR in semiquantitative PCR measurement (Dang et al., 2010). In our study, Q- switch $1064 \mathrm{~nm} \mathrm{Nd:} \mathrm{YAG} \mathrm{laser} \mathrm{stimulated} \mathrm{the} \mathrm{Collagen} \mathrm{I} \mathrm{production}$ in dermis and epidermis, and the maximum increase occurred on 21d irradiation group under the irradiation condition of $1.5 \mathrm{~J} / \mathrm{cm}^{2}$ compared to non-irradiated region (Figure 2). This indicated Q- switch $1064 \mathrm{~nm} \mathrm{Nd}$ : YAG laser irradiation could induce collagen remodeling, and we firstly found the collagen remodeling also happening to epidermis under the $1064 \mathrm{~nm}$ Nd: YAG laser irradiation.

Matrix metalloproteinase (MMPs) could induce dermal collagen degradation (Hinz, 2007). Moreover, MMP-2 was expressed in collagen fibers, and the change of collagens fiber synthesis and decreased MMP-2 expression could cause a change in fibroblast activity (Deveci et al., 2018). Cultured human skin fibroblasts were irradiated twice successively with the $1.5 \mathrm{~J} / \mathrm{cm}^{2}$ of the 532-nm and 1,064-nm Q-switched Nd:YAG lasers, respectively. Both lasers significantly increased the expression of type I and III procollagen, TIMP1 and TIMP2, but decreased MMP1 and MMP2 expression at 24 and $48 \mathrm{~h}$ post-irradiation by using RT-PCR, But the increase/decrease rates of procollagen, TIMPs and MMPs for the 1,064-nm laser were higher than that of the 532-nm laser (Dang et al., 2010). It was consistent with our finding that Q- switch $1064 \mathrm{~nm} \mathrm{Nd:} \mathrm{YAG} \mathrm{laser} \mathrm{induced} \mathrm{decreased}$ MMP2 (Figure 2). The reason for the decreased expression of MMP2 may associated with new collagen synthesis. Present study has reported that hyaluronic acid was injected into the skin, which promoted excisional wound healing by stimulating fibroblasts to express Collagen I, MMP-1 and TIMP-1 (Gao et al., 2010). This showed that TIMP-1 involving in skin rejuvenation. 1,064-nm Q-switched Nd:YAG laser with the $1.5 \mathrm{~J} / \mathrm{cm}^{2}$ increased the expression of TIMP1 and TIMP2 in irradiating cultured human skin fibroblasts (Dang et al., 2010). However, in Lee YB's study, long-pulsed 1,064-nm Nd:YAG laser treatment did not changed the expression of TIMP-1 (Lee et al., 2012). Besides, Oh et al. (2007) also found no significant differences in the expression of TIMP- 1 and 2 levels after nonablative laser treatment (Oh et al., 2007). We adopted Q- switch $1064 \mathrm{~nm}$ Nd: YAG laser irradiation, there was no significant differences in TIMP-1 level in dermis and epidermis (Figure 2). Although the reason for the unchanged expression of TIMP-1 after the laser treatment was not explained in their study. The results of our study are consistent with those of previous studies. These collagen remodeling molecules expression changes of Collagen I, MMP2 and TIMP1 powerfully illustrated that $1064 \mathrm{~nm}$ Q-switched Nd:YAG laser irradiation promoted skin rejuvenation by provoking collagen remodeling in the dermis and epidermis.

Among the MAPK subgroups, both ERK1/2 and p38 MAPK have been known to regulate MMPs gene expression (Brennan et al., 2003). Thus, ERK1/2 and p38 MAPK pathways may involve in protecting intact fibrillar collagen hydrolyzing by regulating MMPs gene expression. In addition, suppressed JNK could lead to the degradation of senescent collagens (Huang et al., 2011). Ye et al. (2012) used $1064 \mathrm{~nm}$ Q-switched Nd:YAG laser at fluences of $0,0.6,1.5$, and $2.5 \mathrm{~J} / \mathrm{cm}^{2}$, respectively, irradiating the dorsal skin of Sprague-Dawley (SD) rats. Then, they found that the $1064 \mathrm{~nm}$ laser treatments led to a marked increase in hydroxyproline/collagen content in a dose-dependent manner.
The expression of Collagen I and III, TIMP1 and TIMP2 in the skin was markedly upregulated, whereas the expression of MMP2 and MMP3 was significantly decreased after laser treatments. Both ERK $1 / 2$ and JNK, MAPK pathways were activated by the $1064 \mathrm{~nm}$ laser irradiation. This indicated that $1064 \mathrm{~nm}$ laser irradiation could markedly increase collagen synthesis and inhibit collagen degradation. The activation of ERK $1 / 2$ and JNK, MAPK pathways induced by the $1064 \mathrm{~nm}$ laser seems to play a role in collagen production in the rat skin (Ye et al., 2012). Based on these previous results, it indicated that the activation of ERK1/2 in dermal fibroblasts was contributed to promote new collagen production while activated JNK played a opposite effect. In our study, we found $1064 \mathrm{~nm}$ Q-switched Nd:YAG laser irradiation activated MAPK family members ERK1/2 and p38 MAPK pathways but not ERK5 signaling pathway, and unactivated JNK pathway (Figure 3).

\section{Conclusion}

To sum up, our study revealed that $1064 \mathrm{~nm}$ Q-switched $\mathrm{Nd}$ :YAG laser irradiation induces collagen remodeling in SKH-1 hairless mice by activating ERK1/2/ p38MAPK signaling pathway. On the other hand, we are still far from a thorough understanding of the molecular and signaling mechanism of this treatment technology of $1064 \mathrm{~nm}$ Q-switched Nd:YAG laser. For a systematic explanation of its skin rejuvenation effect, we still need more research.

\section{References}

Alam, M., \& Dover, J. S. (2003). Nonablative laser and light therapy: an approach to patient and device selection. Skin Therapy Letter, 8(4), 4-7. PMid:12858232.

Alam, M., Hsu, T. S., Dover, J. S., Wrone, D. A., \& Arndt, K. A. (2003). Nonablative laser and light treatments: histology and tissue effects-a review. Lasers in Surgery and Medicine, 33(1), 30-39. http://dx.doi. org/10.1002/lsm.10195. PMid:12866119.

Barone, F., Bashey, S., \& Woodin, F. W. Jr (2019). Clinical evidence of dermal and epidermal restructuring from a biologically active growth factor serum for skin rejuvenation. Journal of Drugs in Dermatology, 18(3), 290-295. PMid:30909351.

Brennan, M., Bhatti, H., Nerusu, K. C., Bhagavathula, N., Kang, S., Fisher, G. J., Varani, J., \& Voorhees, J. J. (2003). Matrix metalloproteinase-1 is the major collagenolytic enzyme responsible for collagen damage in UVirradiated human skin. Photochemistry and Photobiology, 78(1), 43-48. http://dx.doi.org/10.1562/0031-8655(2003)078<0043:MMI TMC>2.0.CO;2. PMid:12929747.

Chan, H. H., Lam, L. K., Wong, D. S., \& Wei, W. I. (2003). Role of skin cooling in improving pateint tolerability of Q-switched Alexandrite (QS Alex) laser in nevus of Ota treatment. Lasers in Surgery and Medicine, 32(2), 148-151. http://dx.doi.org/10.1002/lsm.10112. PMid:12561049.

Chu, Y. H., Chen, S. Y., Hsieh, Y. L., Teng, Y. H., \& Cheng, Y. J. (2018). Low-level laser therapy prevents endothelial cells from TNF- $\alpha$ / cycloheximide-induced apoptosis. Lasers in Medical Science, 33(2), 279-286. http://dx.doi.org/10.1007/s10103-017-2364-x. PMid:29098460.

Dang, Y., Liu, B., Liu, L., Ye, X., Bi, X., Zhang, Y., \& Gu, J. (2011). The $800-\mathrm{nm}$ diode laser irradiation induces skin collagen synthesis by stimulating TGF- $\beta /$ Smad signaling pathway. Lasers in Medical Science, 26(6), 837-843. http://dx.doi.org/10.1007/s10103-0110985-z. PMid:21892789. 
Dang, Y., Ye, X., Weng, Y., Tong, Z., \& Ren, Q. (2010). Effects of the 532-nm and 1,064-nm Q-switched Nd: YAG lasers on collagen turnover of cultured human skin fibroblasts: a comparative study. Lasers in Medical Science, 25(5), 719-726. http://dx.doi.org/10.1007/ s10103-009-0657-4. PMid:20490593.

Demyanenko, S. V., Panchenko, S. N., \& Uzdensky, A. B. (2015). Expression of neuronal and signaling proteins in penumbra around a photothrombotic infarction core in rat cerebral cortex. Biochemistry, 80(6), 790-799. http://dx.doi.org/10.1134/S0006297915060152. PMid:26531025.

Deveci, B., Ayna, B., Tacir, İ. H., Deveci, E., Tuncer, M. C., \& Pala, A. (2018). Effects of nicotine administration in rats on MMP2 and VEGF levels in periodontal membrane. Folia Morphologica, 77(3), 471-477. http://dx.doi.org/10.5603/FM.a2018.0004. PMid:29345720.

Ee, H. L., Goh, C. L., Khoo, L. S., Chan, E. S., \& Ang, P. (2006). Treatment of acquired bilateral nevus of ota-like macules (Hori's nevus) with a combination of the 532nm Q-Switched Nd: YAG laser followed by the $1064 \mathrm{~nm}$ Q-switched Nd: YAG is more effective: prospective study. Dermatologic Surgery, 32(1), 34-40. PMid:16393596.

Farage, M. A., Miller, K. W., Elsner, P., \& Maibach, H. I. (2013). Characteristics of the aging skin. Advances in Wound Care, 2(1), 5-10. http://dx.doi.org/10.1089/wound.2011.0356. PMid:24527317.

Gao, F., Liu, Y., He, Y., Yang, C., Wang, Y., Shi, X., \& Wei, G. (2010). Hyaluronan oligosaccharides promote excisional wound healing through enhanced angiogenesis. Matrix Biology, 29(2), 107-116. http://dx.doi.org/10.1016/j.matbio.2009.11.002. PMid:19913615.

Gold, M. H., Sensing, W., \& Biron, J. (2014). Fractional Q-switched 1,064-nm laser for the treatment of photoaged-photodamaged skin. Journal of Cosmetic and Laser Therapy, 16(2), 69-76. http://dx.doi. org/10.3109/14764172.2013.864197. PMid:24215422.

Goldberg, D. J., \& Metzler, C. (1999). Skin resurfacing utilizing a lowfluence Nd: YAG laser. Journal of Cutaneous Laser Therapy, 1(1), 23-27.

Goldberg, D. J., \& Silapunt, S. (2000). Q-switched Nd: YAG laser: rhytid improvement by non-ablative dermal remodeling. Journal of Cutaneous Laser Therapy, 2(3), 157-160. http://dx.doi. org/10.1080/14628830050516425. PMid:11360334.

Goldberg, D. J., \& Silapunt, S. (2001). Histologic evaluation of a Q-switched $\mathrm{Nd}$ : YAG laser in the nonablative treatment of wrinkles. Dermatologic Surgery, 27(8), 744-746. http://dx.doi.org/10.1097/00042728200108000-00009. PMid:11493299.

Hinz, B. (2007). Formation and function of the myofibroblast during tissue repair. The Journal of Investigative Dermatology, 127(3), 526-537. http://dx.doi.org/10.1038/sj.jid.5700613. PMid:17299435.

Huang, J., Luo, X., Lu, J., Chen, J., Zuo, C., Xiang, Y., Yang, S., Tan, L., Kang, J., \& Bi, Z. (2011). IPL irradiation rejuvenates skin collagen via the bidirectional regulation of MMP- 1 and TGF- $\beta 1$ mediated by MAPKs in fibroblasts. Lasers in Medical Science, 26(3), 381-387. http://dx.doi.org/10.1007/s10103-010-0870-1. PMid:21161310.

Jenkins, G. (2002). Molecular mechanisms of skin ageing. Mechanisms of Ageing and Development, 123(7), 801-810. http://dx.doi.org/10.1016/ S0047-6374(01)00425-0. PMid:11869737.

Kocic, H., Arsic, I., Stankovic, M., Tiodorovic, D., Ciric, V., \& Kocic, G. (2017). Proliferative, anti-apoptotic and immune-enhancing effects of L-arginine in culture of skin fibroblasts. Journal of Biological Regulators and Homeostatic Agents, 31(3), 667-672. PMid:28954469.

Kunimatsu, R., Gunji, H., Tsuka, Y., Yoshimi, Y., Awada, T., Sumi, K., Nakajima, K., Kimura, A., Hiraki, T., Abe, T., Naoto, H., Yanoshita, M., \& Tanimoto, K. (2018). Effects of high-frequency near-infrared diode laser irradiation on the proliferation and migration of mouse calvarial osteoblasts. Lasers in Medical Science, 33(5), 959-966. http:// dx.doi.org/10.1007/s10103-017-2426-0. PMid:29302842.
Lee, J. H., Park, S. R., Jo, J. H., Park, S. Y., Seo, Y. K., \& Kim, S. M. (2014). Comparison of epidermal/dermal damage between the longpulsed $1064 \mathrm{~nm} \mathrm{Nd}$ : YAG and $755 \mathrm{~nm}$ alexandrite lasers under relatively high fluence conditions: quantitative and histological assessments. Photomedicine and Laser Surgery, 32(7), 386-393. http://dx.doi. org/10.1089/pho.2013.3665. PMid:24992273.

Lee, Y. B., Kang, N. H., Eun, Y. S., Cheon, M. S., Kim, K. M., Cho, B. K., \& Park, H. J. (2012). Effects of long-pulsed 1,064-nm neodymiumdoped yttrium aluminum garnet laser on dermal collagen remodeling in hairless mice. Dermatologic Surgery, 38(7), 985-992. http://dx.doi. org/10.1111/j.1524-4725.2012.02374.x. PMid:22404226.

Nikolaou, V. A., Stratigos, A. J., \& Dover, J. S. (2005). Nonablative skin rejuvenation. Journal of Cosmetic Dermatology, 4(4), 301-307. http:// dx.doi.org/10.1111/j.1473-2165.2005.00210.x. PMid:17168881.

Oh, J., Kim, N., Seo, S., \& Kim, I. H. (2007). Alteration of extracellular matrix modulators after nonablative laser therapy in skin rejuvenation. The British Journal of Dermatology, 157(2), 306-310. http://dx.doi. org/10.1111/j.1365-2133.2007.08061.x. PMid:17650176.

Quan, T., He, T., Kang, S., Voorhees, J. J., \& Fisher, G. J. (2004). Solar ultraviolet irradiation reduces collagen in photoaged human skin by blocking transforming growth factor-beta type II receptor/Smad signaling. The American Journal of Pathology, 165(3), 741-751. http://dx.doi.org/10.1016/S0002-9440(10)63337-8. PMid:15331399.

Rhee, Y., Cho, H. I., Park, G. H., Moon, H. R., Chang, S. E., Won, C. H., Jung, J. M., Park, K. Y., Lee, M. W., Choi, J. H., Moon, K. C., Lee, D. C., \& Goo, B. (2016). Histological and molecular analysis of the long-pulse 1,064-nm Nd: YAG laser on irradiation the ultravioletdamaged skin of hairless mice: In association with pulse duration change. Journal of Cosmetic and Laser Therapy, 18(1), 16-21. PMid:26052812.

Ryu, A. R., \& Lee, M. Y. (2017). Chlorin e6-mediated photodynamic therapy promotes collagen production and suppresses MMPs expression via modulating AP-1 signaling in P. acnes-stimulated HaCaT cells. Photodiagnosis and Photodynamic Therapy, 20, 71-77. http://dx.doi.org/10.1016/j.pdpdt.2017.08.002. PMid:28807774.

Shin, M. K., Lee, J. H., Lee, S. J., \& Kim, N. I. (2012). Platelet-rich plasma combined with fractional laser therapy for skin rejuvenation. Dermatologic Surgery, 38(4), 623-630. http://dx.doi.org/10.1111/j.15244725.2011.02280.x. PMid:22288389.

Tao, L., Wu, J., Qian, H., Lu, Z., Li, Y., Wang, W., Zhao, X., Tu, P., Yin, R., \& Xiang, L. (2015). Intense pulsed light, near infrared pulsed light, and fractional laser combination therapy for skin rejuvenation in Asian subjects: a prospective multi-center study in China. Lasers in Medical Science, 30(7), 1977-1983. http://dx.doi.org/10.1007/ s10103-015-1792-8. PMid:26266401.

Wang, X., Yang, Z., Xiong, Y., Wan, P., He, L., Chen, Y., Jiang, S., Su, H., Zhang, Y. Q., \& Du, Y. F. (2016). The effects of different fluences of $1064 \mathrm{~nm}$ Q-Switched Nd: YAG laser on skin repair and skin barrier dysfunction in mice. Photomedicine and Laser Surgery, 34(2), 76-81. http://dx.doi.org/10.1089/pho.2015.3921. PMid:26840551.

Yaar, M., \& Gilchrest, B. A. (2007). Photoaging: mechanism, prevention and therapy. The British Journal of Dermatology, 157(5), 874-887. http://dx.doi.org/10.1111/j.1365-2133.2007.08108.x. PMid:17711532.

Ye, X., Wang, L., Dang, Y., Liu, B., \& Zhao, D. (2012). Investigation of the $1064 \mathrm{~nm}$ Q-switched Nd: YAG laser on collagen expression in an animal model. Photomedicine and Laser Surgery, 30(10), 604-609. http://dx.doi.org/10.1089/pho.2012.3221. PMid:22974369.

Zhen, L. I. (1997). The effects antiaging traditional Chinese medicine to the quantities of hydroxyproline in the skin of mice. Journal of Shandong University of Chinese Medicine, 21, 142-143.

Zhou, Z. Q., \& Yang, R. Y. (2015). Clinical progresses on non-surgical facial rejuvenation. Journal of Practical Dermatology, 8, 438-444. 